\title{
A cell capsule with possible involvement in resistance to opsonophagocytosis in Enterococcus seriolicida isolated from yellowtail Seriola quinqueradiata
}

\author{
T. Yoshida ${ }^{1, *}$, M. Endo ${ }^{1}$, M. Sakai ${ }^{1}$, V. Inglis ${ }^{2}$ \\ ${ }^{1}$ Department of Fisheries, Faculty of Agriculture, Miyazaki University, Miyazaki 889-21, Japan \\ ${ }^{2}$ Institute of Aquaculture, University of Stirling, Stirling FK9 4LA, Scotland, UK
}

\begin{abstract}
A cell capsule was revealed by transmission electron microscopy on the surface of non-agglutinating $(\mathrm{KG}-)$, but not on agglutinating $(\mathrm{KG}+)$, cells of the bacterial fish pathogen Enterococcus seriolicida. The capsule of $\mathrm{KG}-$ cells may be involved in resistance to opsonophagocytosis by head kidney phagocytes of yellowtail Seriola quinqueradiata.
\end{abstract}

KEY WORDS: Capsule Fish pathogen Anti-opsonophagocytosis - Enterococcus seriolicida $\cdot$ Seriola quinqueradiata

Enterococcal infection of yellowtail Seriola quinqueradiata caused by Enterococcus seriolicida is a serious bacterial disease in Japan (Kitao 1993). Recently, Eldar et al. (1996) and Teixeira et al. (1996) suggested E. seriolicida should be re-classified into a synonym of Lactococcus garvieae by DNA-DNA homologies.

Enterococcus seriolicida has been divided into nonagglutinating ( $\mathrm{KG}-$ ) and agglutinating $(\mathrm{KG}+)$ phenotypes by anti-KG+ serum. This antigenic variation arises after subculturing fresh isolates ( $\mathrm{KG}$ - phenotype) on Todd Hewitt agar (THA; Difco Laboratories, Detroit, USA) or on Streptococcus agar (KF Streptococcus agar; Difco) supplemented with 2,3,5-triphenyltetrazolium chloride (Kitao 1982). KG-phenotype isolates are more hydrophilic than $\mathrm{KG}+$ cells, resist phagocytosis and reduce chemiluminescent responses by yellowtail head kidney phagocytes. KG+ cells elicit higher serum agglutinating titers in yellowtail than the $\mathrm{KG}$ - phenotype. A cell surface, putative capsular material demonstrated by scanning electron microscopy may function as an anti-phagocytic factor in E. seriolicida and affect its immunogenicity in yellowtail (Yoshida et al. 1996a). The previous study could not confirm the presence of a capsule in KG-cells. This study demonstrates the presence of a capsule in E. seriolicida KG-phenotype cells.

·E-mail:a0c201u@cc.miyazaki-u.ac.jp
Materials and methods. Bacteria: The Enterococcus seriolicida isolates used were obtained from diseased yellowtail in Japan (Table 1). The bacteria were maintained at $-70^{\circ} \mathrm{C}$ in $15 \%$ (vol/vol) glycerol-Todd Hewitt broth and cultured in Todd Hewitt broth (THB) for $24 \mathrm{~h}$ at $25^{\circ} \mathrm{C}$ before use. The cell phenotype was confirmed using a rabbit antiserum against $\mathrm{KG}$ - or $\mathrm{KG}+$ cells $\mathrm{KG}+$ cells were obtained following several passages of the $\mathrm{KG}$ - phenotype on THA.

Preparation of antiserum: An antiserum against $\mathrm{KG}$ - cells was raised as described by Yoshida et al. (1996a). An anti-KG7409(KG-cells) rabbit serum with a titer of 1:1280 (agglutinating titer) against the homologous phenotype cells was used.

Quellung test: The Quellung test (Austrian 1976) was modified using rabbit anti-KG-cell serum. Briefly, cells of both phenotypes were suspended in phosphate-buffered saline (PBS) $\left(\mathrm{OD}_{660 \mathrm{~nm}}=0.6\right)$. Methylene blue $(0.1 \mathrm{ml}, 1 \%)$ was mixed with $0.1 \mathrm{ml}$ cell suspension, and $20 \mu$ laliquots were spotted on glass slides and air dried. Anti-KG-cell serum was placed on the spots which were then covered with a coverslip. Slides were examined by phase contrast microscopy (magnification $\times 1000$ ). Cell capsules appeared as a halo surrounding the bacterial cell.

Confirmation of cell capsule by staining: A bacterial suspension of $10^{5}$ colony forming units (CFU) $\mathrm{ml}^{-1}$ in PBS was mixed with an equal volume of Indian ink (Yoshida et al. 1996b). Capsules were also stained by Muir's method (Cowan \& Steel 1965). Capsule-positive control bacteria were $\beta$-haemolytic Streptococcus spp. MZ9301 isolated from rainbow trout Oncorhynchus mykiss (Yoshida et al. 1996b).

Electron microscopy: Enterococcus seriolicida, $\mathrm{KG-}$ and $\mathrm{KG}+(\mathrm{NG} 8206, \mathrm{KG} 7409$ and MZ9501) were grown overnight in $10 \mathrm{ml}$ of THB, diluted 1:100 in fresh THB and incubated for an additional $5 \mathrm{~h}$ at $25^{\circ} \mathrm{C}$. Bacteria 
Table 1. Strains of Enterococcus seriolicida used in this study and their properties

\begin{tabular}{|c|c|c|c|c|c|}
\hline \multirow[t]{2}{*}{ Strain (phenotype) } & \multirow[t]{2}{*}{ Location } & \multicolumn{2}{|c|}{ Antiserum } & \multirow{2}{*}{$\begin{array}{c}\text { No. of } \\
\text { subcultures }\end{array}$} & \multirow{2}{*}{$\begin{array}{l}\text { Capsule } \\
\text { by TEN }\end{array}$} \\
\hline & & KG7409(-) & KG7409(+) & & \\
\hline NG8206 (KG-) & Nagasaki & + & - & 5 & + \\
\hline NG8206 $(\mathrm{KG}+)$ & Nagasaki & + & + & 10 & - \\
\hline $\mathrm{KG} 7409(\mathrm{KG}-)$ & Kagoshima & + & - & 7 & + \\
\hline $\mathrm{KG} 7409(\mathrm{KG}+)$ & Kagoshima & + & + & 20 & - \\
\hline MZ9501 (KG-) & Miyazaki & + & - & 3 & + \\
\hline MZ9501 (KG+) & Miyazaki & + & + & 9 & - \\
\hline
\end{tabular}

were added to $0.3 \%$ formalin and held overnight at $4^{\circ} \mathrm{C}$. The killed cells were washed 3 times with PBS and resuspended in $10 \mathrm{ml}$ of $\mathrm{KG}$ - antiserum (1:1280) diluted 1:640 with PBS and incubated for $10 \mathrm{~h}$ at $4^{\circ} \mathrm{C}$. Bacteria were washed 3 times with PBS and capsules were stained with $0.15 \%$ ruthenium red (Sigma, St. Louis, USA) in $2 \%$ glutaraldehyde-0.1 $\mathrm{M}$ cacodylate buffer, pH 7.4, for $2 \mathrm{~h}$. Bacteria were washed 3 times with the same buffer, embedded in $3 \%$ agarose, washed 5 times in buffer, fixed with $2 \%$ osmium tetroxide, washed 5 times with buffer, and dehydrated with ethanol. After 5 washes with propylene oxide, the cells were embedded in Quetol 651 (Nishin EM, Tokyo, Japan). Thin sections were postfixed with uranyl acetate and lead acetate, then observed by transmission electron microscopy (Hitachi-H4800MU, Japan) at an accelerating voltage of $100 \mathrm{kV}$.

Attachment or ingestion of bacteria by head kidney cells: A phagocytosis test was performed as described by Yoshida et al. (1996a). Equal volumes of $\mathrm{KG}$ - or

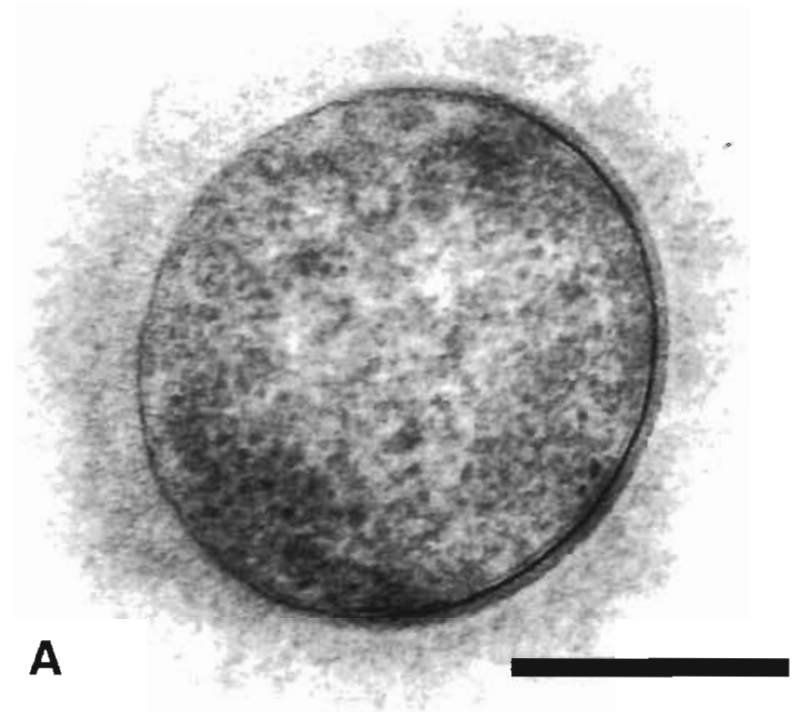

$\mathrm{KG}+\left(1.0 \times 10^{6}\right.$ cells $\left.\mathrm{ml}^{-1}\right)$ and yellowtail normal pooled serum $(n=5)$ were mixed and incubated at $4^{\circ} \mathrm{C}$ for $1 \mathrm{~h}$. Cells then were washed 3 times with Hanks' balanced salt solution (HBSS), and adjusted to an optical density of 0.6 at $620_{\mathrm{nm}}$ in HBSS. Head kidney phagocytic cells from yellowtail with mean body weight $1250 \mathrm{~g}(\mathrm{n}=5)$ were obtained by the density gradient centrifugation method described by Braun-Nesje et al. (1982). Purified head kidney cells were adjusted to $6.0 \times 10^{6}$ cells $\mathrm{ml}^{-1}$ in HBSS and allowed to adhere to a coverglass for 2 h. Previously opsonized Enterococcus seriolicida $\mathrm{KG}$ - or KG+ cells (100 $\mathrm{kl}$ each) were overlayed and incubated at $25^{\circ} \mathrm{C}$ for $1 \mathrm{~h}$, rinsed with HBSS to remove free bacteria, then fixed with methanol. The cells were visualized by Giemsa staining. The number of phagocytes containing or associated with more than 5 bacteria per 100 glass-adherent cells were examined microscopically. Adherent cells such as lymphocytes were disregarded. Statistical significance for phagocytic rate was assessed using Student's t-test.

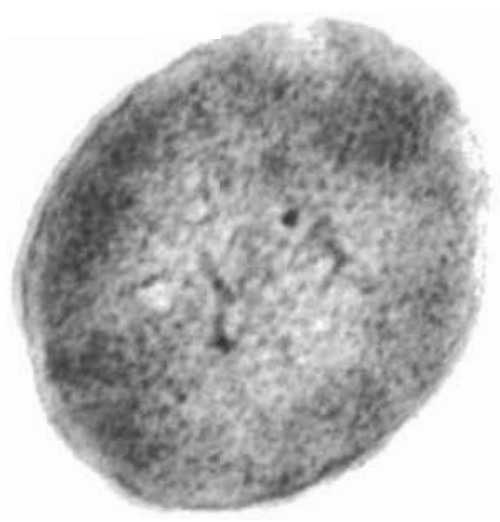

\section{B}

Fig. 1. Electron micrograph of Enterococcus sersolicida MZ9501 (KG-and KG+ phenotype). (A) Cell incubated with antiserum $(\mathrm{KG}-$ type) and stained with ruthenium red demonstrating an electron faint layer adjacent to the cell wall (original magnification, $\times 60000)$. (B) $\mathrm{KG}+$ cell showing no layer on the cell surface (original magnification $\times 60000$ ). Scale bar $=500 \mathrm{~nm}$ 
Table 2. Phagocytic response of yellowtail Seriola quinqueradiata phagocytic cells against the $\mathrm{KG}$ - and $\mathrm{KG}+$ phenotypes of Enterococcus seriolicida. "Value significantly lower than the value of $\mathrm{KG}+$ phenotype cells $(p<0.05\}$

\begin{tabular}{|lc|}
\hline Strain (phenotype) & Phagocytic rate $(\%)$ \\
\hline NG8206 (KG-) & $10.0 \pm 5.1^{\circ}$ \\
NG8206 (KG+) & $25.0 \pm 9.4$ \\
KG7409 (KG-) & $11.0 \pm 3.3$ \\
KG7409 (KG+) & $20.6 \pm 7.8$ \\
MZ9501 (KG-) & $8.0 \pm 4.4^{\circ}$ \\
MZ9501 (KG+) & $20.2 \pm 5.5$ \\
\hline
\end{tabular}

Results and discussion. No visible capsule was detected by light microscopy around Enterococcus seriolicida $\mathrm{KG}$ - or $\mathrm{KG}$ + cells in all tested strains stained by Muir's, Quellung, or Indian ink. However, thin sections stabilized with antiserum and stained with ruthenium red demonstrated an electron faint layer on the surface of all KG-phenotype cells (Fig. 1A). No visible surface layer was seen on the surface of KG+ phenotype cells (Fig. 1B). A previous study (Yoshida et al. 1996a) revealed surface clumps on KG-cells by scanning electron microscopy (SEM). A surface layer was shown to be present by transmission electron microscopy in this study and could represent a cell capsule in E. seriolicida KG-phenotype cells

Streptococcus pneumoniae and other Gram-positive pathogens produce exopolysaccharide capsules which contribute to virulence with resistance to phagocytosis as opposed to unencapsulated strains (Williams 1988). In earlier studies (Yoshida et al. 1996a) KG-cells were resistant to opsonophagocytosis by yellowtail head kidney phagocytes and this is supported here (Table 2). Opsonization depends on the binding of complement or antibodies at the bacterial cell surface (Arduino et al. 1994) and may be less efficient in the presence of a capsule, and therefore inversely related to the thickness of the capsule in the $\mathrm{KG}$ - phenotype. Kitao (1983) and Alim et al. (1996) showed KG-cells are more virulent than $\mathrm{KG}+$ phenotype by means of a challenge test. The KG- factor (capsular materials) could be related to a virulence factor in Enterococcus seriolicida.

Enterococcus seriolicida readily underwent phenotypic conversion by subculture on artificial medium. This phenotypic conversion was dependent upon the bacterial strains as some were changed within 5 subcultures whereas other required longer subculture. Cells intermediate between $\mathrm{KG}$ - and $\mathrm{KG}+$ cells were identified by slide agglutination using $\mathrm{KG}-$ and $\mathrm{KG}+$ antiserum. Electron microscopy revealed the varying thickness and partial deficiency in the surface capsule, and these characteristics may be related to an intermediate phenotype. Further studies are in progress to identify the deficiency in KG-capsular materials.

Acknowledgements. This study was partly supported by a Grant-in-Aid for Scientific Research from the Ministry of Education, Science and Culture of Japan

\section{LITERATURE CITED}

Alim SR, Kawai K, Kusuda R (1996) Comparative pathogenicity study on antigenically variant strains of Enterococcus seriolicida. J Fish Dis 19:39-46

Arduino RC, Murray BE, Rakita RM (1994) Roles of antibodies and complement in phagocytic killing of enterococci. Infect Immun 62:987-993

Austrian R (1976) The quellung reaction, a neglected microbiologic technique. Mt Sinai J Med 43:699-709

Braun-Nesje R, Kaplan G, Seljelid R (1982) Rainbow trout macrophages in vitro: morphology and phagocytic activity. Develop Comp Immunol 62:281-291

Cowan ST, Steel KJ (1965) Manual for the identification of medical bacteria. Cambridge University Press, Cambridge

Eldar A, Ghittino C, Asanta L, Bozzetta E, Goria M, Prearo M, Bercovier H (1996) Enterococcus seriolicida is a junior synonym of Lactococcus garvieae, a causative agent of septicemia and meningoencephalitis in fish. Curr Microbiol 32:85-88

Kitao T (1982) The methods for detection of Streptococcus sp., causative bacteria of streptococcal disease of cultured yellowtail, Seriola quinqueradiata, especially, their cultural, biochemical and serological properties. Fish Pathol $17: 17-26$

Kitao T (1983) Strain variation associated with pathogenesis of Streptococcus sp., the causative agent of streptococcosis in cultured yellowtail, Seriola quinqueradiata. In: Proc 2nd Natl Pacific Aquaculture Symp, Tokyo and Shimizu, Japan, 1983. Tokai University, Shimizu, p 231-242

Kitao T (1993) Streptococcal infection. In: Inglis V, Roberts RJ, Bromage NR (eds) Bacterial diseases of fish. Blackwell Scientific Publications, Oxford, p 196-210

Teixeira LM, Merquior VLC, Vianni MCE, Carvalho MGS, Fracalanzza SEL, Steigerwalt AG, Brenner DJ, Facklam RR (1996) Phenotypic and genotypic characterization of atypical Lactococcus garvieae strains isolated from water buffalos with subclinical mastitis and confirmation of $L$. garvieae as a senior subjective synonym of Enterococcus seriolicida. Int J Syst Bacteriol 46:664-668

Williams P (1988) Role of the cell envelope in bacterial adaptation to growth in vivo in infections. Biochimie 70 : $987-1011$

Yoshida T, Eshima T, Wada Y, Yamada Y, Kakizaki E, Sakai M, Kitao T, Inglis V (1996a) Phenotypic variation associated with an anti-phagocytic factor in the bacterial fish pathogen Enterococcus seriolicida. Dis Aquat Org 25: $81-86$

Yoshida T, Yamada Y, Sakai M, Inglis V, Xie XJ, Chen SC, Kruger R (1996b) The association of the cell capsule with anti-opsonophagocytosis in $\beta$-hemolytic Streptococcus spp. isolated from rainbow trout, Oncorhynchus mykiss. J Aquat Anim Health 8:181-186

Manuscript first received: November 12, 1996

Revised version accepted: March 25, 1997 